\title{
Why Maritime Strategy
}

\author{
Keith E. Blount
}

\section{Setting the scene}

This publication sets an ambitious, yet fundamentally important agenda to look at allied strategic thought in the maritime sphere and revisit the current Alliance Maritime Strategy of 2011 in the light of recent and indeed future geopolitical developments. The end of the Cold War marked not so much a finish line as the starting gun of a new race that has not yet been won. Indeed, the distance over which the course is set, its obstacles and even those competing is ever changing. This conundrum creates huge academic and, of course, military interest, and the need to get and stay ahead of events is a profound and ongoing challenge. Some would argue that we in NATO have been slightly off the pace and what is needed now is a spurt to regain control of the competition. I assert that we are doing just that, and that there is much to be confident about. NATO's new Military Strategy (NMS) of May 2019, the first in almost 50 years, has prompted a broad swathe of follow-on work, with the Concept for Deterrence and Defence of the Euro-Atlantic Area (DDA) forming the spine. Subordinate Directives and Plans are already in work and will form the core of NATO's new thinking and writing in 2021. Furthermore, NATO is embracing the challenges set by new competitors in an age of new competition through its NATO 2030 work. NATO's 'ends, ways and means' are all being discussed and this publication will doubtless advance the debate. There is an urgency to do all of this work fast and well and I, as NATO's Maritime Commander and principal maritime advisor, will be kept busy as the maritime domain features prominently throughout.

\section{Do we need to change?}

There is always a push for change. Whether it is the media, academics, or new and energetic military Commanders, we are all encouraged to drive change. However, this clamour for change does sometimes need a little tempering and adjudication by the 'if it ain't broke' maxim. Unquestion- 
ably, the catalytic events of 1989-1991 required the complete recalibration of NATO, and while some would argue that getting to its Strategic Concept of 2010 was a journey conducted at a somewhat pedestrian pace, what it delivered was totemic. Above all else, it placed the core tasks and principles of collective defence, crisis management and cooperative security at equal importance. It introduced the need for NATO to orientate itself to new threats and challenges such as cyber and energy security and the emergence of new technologies. It also created a vision of 'nuclear zero' and kept the door open for further enlargement-all this within a wrapper of cost effectiveness for the taxpayer. These strategic pillars and themes still sound fresh and right. When the Allied Maritime Strategy (AMS) followed in 2011, its opening words sound remarkably contemporary, even 11 years on:

"The evolving international situation of the 21st century heralds new levels of interdependence between states, international organisations and non-governmental organisations, the increasing complexity of global commerce, and potential threats from both state and non-state actors. Combined with the rapid spread of advanced weapons such as high-performance aircraft, submarines, and precision-guided munitions, the alliance may be challenged in mission areas it has traditionally dominated." 1

The Strategy's themes expanded upon the three strategic pillars within the Strategic Concept and added a fourth, that of maritime security. This allowed maritime thinking to range from the classical Article V, high-end conflict to more constabulary-orientated tasks and law enforcement. Given the scourge of Indian Ocean piracy at the time and NATO's response in the form of Operation OCEAN SHIELD, it was unquestionably right then and still feels right now. The strategic building blocks created over 10 years ago are hard to argue with, but they do need to be refocused in terms of 'what's new'. Put another way, where the cornerstones of the strategy seem right, there remains the need for updated thinking on how and where we should be applying them-and against whom.

1 NATO, 11 June 2011, Alliance Maritime Strategy, www.nato.int/cps/en/natohq/offic ial_texts_75615.htm, accessed 15 January 2021. 
There are a lot of contemporary challenges that keep me thinking and to varying degrees concern me. Positively, as I will outline, they are all being carefully considered within NATO's ongoing work following the NMS, and I feel able to influence their trajectory and focus. This important and timely volume provides the reader with an excellent stocktake of many current and future challenges. By way of a primer, let me elaborate on some of the key themes in my 'in tray' and then explain in a little detail what we're doing about them.

It's still (mostly) about Russia. Russia remains the competitor that attracts NATO's greatest strategic focus. The attempted recapitalisation of its fleet, however, hasn't been without challenges or failure. The 2005 headmark to build a new class of aircraft carriers (sea trials were forecast for 2017) ${ }^{2}$ is yet to materialise. The Yasen-class submarine, while very capable, has its origins as far back as 1977 . The solitary commissioned vessel in the class, Severodvinsk, has already become somewhat of a workhorse before the second boat, the Kazan, has been commissioned. And, the Lider-class 'Aegislike' destroyer programme appears to have been cancelled in toto. However, before we relax too much, we should remember that Russia is very good at keeping old vessels running. No one should take the Delta, Oscar, Victor, Sierra, Akula, Kilo or other 'research' class submarines for granted. We should take careful note of the 'kalibrisation' of its forces and of the six classes of patrol vessels Russia is building quickly_all of them deployable, Kalibr capable and operating as an effective extension to shore-based A2AD systems. We should also remember the advantages of common equipment throughout every class, the same communications systems, EW systems, training, tactics, rules of engagement, etc., which all serve to give Russia tempo. Add to this, a political and cultural will to reassert its military adventurism and indeed extend it and Russia remains a very credible maritime nation.

Suddenly, China has arrived too. The PLA(N) has built the equivalent tonnage to that of the current Royal Navy in the last 5 years $^{3}$ and is using it further afield more regularly. I blame some of this on the Somali pirates. The way in which nations with differences converged on the Gulf of Aden

2 Ilya Kramnik, 20 May 2013, Russian Aircraft Carriers: time to grasp the nettle, Russian International Affairs Council.

3 John Harper, 3 September 2020, Eagle vs Dragon: How the US and Chinese Navies Stack Up, National Defense Magazine. 
and the Indian Ocean ten years ago was trumpeted as a triumph of international responsiveness in the face of a threat to the global economy. The Chinese were one of the first navies to arrive and quickly got the hang of it. Setting their escort routes up to the north of the Internationally Recommended Transit Corridor, they got the taste for out-of-area deployment as a group, so much so that they started to arrive with that niche counter piracy asset, the nuclear powered submarine. Then they-and many other nations - built a base in Djibouti. Now China is a permanent fixture in the region, able to sustain expeditionary operations, while still conducting its counter piracy patrols. The proximity to the Mediterranean through the Suez has seen some deployed task groups returning home the long way, and while we still tend to point at Chinese warships in the NATO area of responsibility in the same way people used to point at aeroplanes, they are by no means uncommon. However, despite a fleet size soaring towards 400 warships, it is China's economic involvement in the European theatre that is perhaps most thought-provoking. By 2018, the state-owned COSCO Shipping Ports and the Chinese Merchants Port Holdings had financial interests in 13 European and Mediterranean ports, forming the maritime flank of the Belt and Road Initiative. ${ }^{4}$ The big and mysterious question is 'what's it all for?'

International terrorism. The general trend of international terrorism has been downward since 2014. ${ }^{5}$ However, the global pandemic is forecast to bring somewhat of a resurgence in its wake. ${ }^{6}$ Economic downturns and the hardship they create, continued migration, deepening interstate friction, new administrations, further acceleration of technologies such as AI and the even wider use of/reliance on social media all present opportunities to terrorists. Increasingly blurred boundaries between state, non-state and non-aligned actors and their potential spillover into the murky world of the 'grey zone' won't help. Neither will the time lockdown has provided the malfeasant terrorists to think and plan. We remain postured resolutely against terrorism and will, I fear, remain so for the foreseeable future.

The capability challenge. Keeping ahead of the threat is the essence of winning, but it isn't easy. The logarithmic acceleration of technology commonly outstrips procurement processes. Capabilities that were hitherto

4 Louise Vogdrup-Schmidt, 29 January 2018, Chinese Investors own 10 per cent of Europe's Ports, Shipping Watch.

5 Statistics vary, but the general trend is widely accepted. See, for example, www.stati sta.com/statistics/271514/global-terrorism-index, accessed 13 January 2021.

6 See, for example, Colin P Clarke, 5 January 2021, Trends in Terrorism: What's on the Horizon in 2021?, FPRI. 
thought of as domestic security challenges, such as cyber ones, are being militarised and weaponised, challenging not only the ways of war (and peace), but the manner in which governments and defence departments are structured and organised. Parochially, from the maritime perspective, while space prevents a deeper analysis, I would point to the underwater domain as the one that requires most work. Traditional ASW has effectively been recast as Undersea Warfare (USW). Protecting submarines and ships of all kinds of course remains important, as does denying any enemy their use. However, add to the mix the estimated 1.2 million $\mathrm{km}$ of undersea cables that transact $99 \%$ of the world's data ${ }^{7}$ (and the fact there are helpful charts on the internet to tell you where they are), and we have a new and escalating challenge that is yet to be fully met. I will also mention briefly hypersonics and carriers because they form an interesting and trending topic. I acknowledge that China and Russia are experimenting with hypersonic missiles ${ }^{8}$. I would, however, argue that the determination and attendant costs required to achieve any such capability underline the value in which carriers are still held. The fact that aircraft carriers around the world are being built faster and in greater numbers than at any time since World War 2 reinforces the point. I would also assert that if it is in your strategic calculus (for it is strategic) that on a given day you will try to sink one of NATO's super carriers, you had better have thought through the next move on the chess board, for whether you hit it or miss it, the consequences are likely to be the same.

NATO's new frontiers. There is no question that the boundaries of NATO's AOR are being stretched and the areas in which we should operate are discussed and debated frequently. There are, of course, policy and political decisions needed to change our established boundaries (as was the case with Afghanistan, Iraq and the Horn of Africa), but the reasons why this is an important topic are clear. One factor is that globalisation is not only being enabled by technology, but also through climate change. The connectivity of east to west (globalisation works both ways!) is becoming easier through the Northern Sea Route. Russia's impending Chairmanship of the Arctic Council will most likely lead to Russia seeking to normalise its role as the region's 'steward', ' which would do little to smooth the

7 See, Submarine Cable 101, at www2.telegeography.com/submarine-cable-faqs-frequ ently-asked-questions, accessed 5 January 2021.

8 See, for example, Benjamin Brimelow, 10 January 2021, US aircraft carriers still rule the seas, but Russia and China both have plans to change that, Business Insider.

9 Dr Elizabeth Buchanan, 4 January 2021, Russia Plants a Further Flag in the Arctic, High North News. 
nascent economic, territorial and other security tensions that already exist. Routinely exploited by Russia, increasingly China and with the help of a building fleet of ice breakers, the Northern Sea route-in a potential rather than absolute sense at the moment-is a strategic issue. Equally, however, our frontiers are being extended by domain-principally upwards into space. Both it and cyberspace form the new domains that we are seeking to link through the variously labelled Multi Domain (MDO) or All Domain Operations. ${ }^{10}$ This creates new challenges and opportunities, applies inherent 'hybridisation' to our planning and thinking, and poses subsequent questions relating to the balance between soft and hard power and the very foundations of how deterrence works.

\section{What are we doing about it?}

Future thinking-NATO 2030. NATO recently published 'NATO 2030 United for a New Era'. ${ }^{11}$ It is a report by an appointed 'Reflections Group' and as such is not decisional, but it does get to grips with the themes I have outlined above. From a maritime perspective, it is very helpful. It is clear on RFN regeneration, risks at choke points and the burgeoning Northern Sea Route. It calls for the establishment of a NATO consultative body on China, which it identifies as a competitor, and recommends that 'NATO must devote much more time, political resources and action to the security challenges posed by China. ${ }^{12}$ It ranges across the geopolitics of the Arctic and promotes a new Centre of Excellence on Climate and Security. It continues to encourage a determined boot held firm on the neck of terrorism. And it welcomes the new domain of space, underlining the importance of space security throughout and linking it with the other domains. In sum, the document reads as a 'strategy in waiting' and its most fundamental and important call is for a new Strategic Concept to update that written in 2010.

DDA and NATO Command Structure Adaptation (NCSA). However, strategy is not just about writing strategy. It is also about thinking strategically, and the NMS and DDA have catalysed this. The DDA is the core executable document to stimulate thought and is very maritime-focused; not

10 Cyberspace was recognised as a domain at the Warsaw Summit in 2016 and space was established as a NATO domain in 2019.

11 Available at: www.nato.int/nato_static_fl2014/assets/pdf/2020/12/pdf/201201-Refl ection-Group-Final-Report-Uni. pdf, accessed 14 January 2020.

12 ibid., 12. 
in any skewed or disproportionate way, but simply because $80 \%$ of SACEUR's AOR is indisputably wet.

At its heart, the DDA makes abundantly clear the need to be ready to fight and win, but moreover that we must continue to win the peace. In this sense, deterrence must be decisive. The DDA provokes thinking on managing deterrence by maintaining a deterrence posture, ultimately set by SACEUR. In the maritime sphere, an overall awareness of the domain is the starting point, where intelligence and the operational plot of 'blue and red' are fused and disseminated. The new Standing NATO Maritime Framework (SNMF) provides the ways and means of achieving this. The SNMF seeks to ensure that the traditional building blocks of deterrencecapability, intent and communication - are cohered and aligned in a way that 'joins up the blue dots'. Allied activity should be harmonised for its deterrent effect to be clear and unambiguous. The DDA applies a sophistication to deterrence thinking and is designed to prevent unnecessary provocation or miscalculation. Too often we are ready to react to Russian activity by simply shadowing it and giving it a hard stare. This 'kiddies' football' analogy of simply 'following the ball' is not my idea of deterrence: it must be thoughtful and responsible.

The adaptation of NATO's Command Structure (NCSA) has delivered a bigger headquarters for MARCOM. It will provide us with deeper and broader expertise to command in peace or war and establishes my role as NATO's Maritime Theatre Component Commander. Furthermore, the NCSA has seen the formation of a new Joint Forces Command (JFC) in Norfolk, Virginia. This Atlantic-focused Command provides further deep understanding of the AOR in this critical region. It, of course, recognises the resurgence of Russia's naval activity and provides further resilience to the command structure, but in peace its fundamental role is to ensure we get deterrence right.

The role of NATO's standing forces is reinforced through the DDA. As the very front line of all maritime activity in peace, crisis or conflict, permanently formed groups of ships have been a fixture in NATO's force structure since the idea of Standing Naval Force Atlantic was conceived by Admiral Richard G. Colbert in 1968. The established force generation process sees nations committing ships to one of the four groups for six-month periods, during which they operate under MARCOM command. However, while the DDA doesn't challenge this norm, it encourages short-notice, staccato contributions from vessels operating under national command, which temporarily transfer the authority of command to MARCOM to respond to any given situation and augment the Standing Forces. For nations, this is as much about a new way of thinking as it is 
doing, and its early successes have been very promising. Again, it's all about 'joining up the blue dots'.

The threat of terrorism is met, head on, in the DDA and features prominently in MARCOM's daily business. Operation SEA GUARDIAN (OSG) is centred on countering terrorism and is a 24/7 activity 365 days a year. Targeted Focused Operations augment daily business. Again, all of this is underpinned by maritime situational awareness and the willingness of nations to contribute. 'Associated Support' (AS) to operations is a way in which nations bolster NATO activity while operating under national command. Unlike the pulsed contributions to the Standing Forces, it doesn't involve a change of $\mathrm{C} 2$, but requires vessels and aircraft to be alert and report what they see. It is ideally suited to OSG and last year saw an increase of more than $100 \%$ in AS contributions, which was extraordinary. As such, OSG continues to be a successful operation and has been very important in spreading the word of NATO generally and the NATO Shipping Centre specifically. Furthermore, it provides daily reassurance to the merchant marine sector that NATO is watching over them.

Future capability and warfighting. In parallel with the NMS, NATO has been writing a further strategic document titled the NATO Warfighting Capstone Concept. This is an equally seminal piece, authored by Allied Command Transformation, which is set within a 20 -year horizon. It is an overarching concept that guides NATO's future warfare development and will inform the NATO Defence Planning Process, which aims to ensure nations are properly equipped to meet the threats of today and those in the future. MARCOM has added its input to it, and the need to keep pace with USW is reflected well. However, one of the inevitable-and helpful-conclusions of this work is to reaffirm the need to extend our thinking, tactics, training and procedures beyond the 'Joint' domain, which considers warfare in a functional way, ${ }^{13}$ to the 'multi-domain', which considers how warfighting needs to be harmonised across the five warfighting domains. ${ }^{14}$ Accompanying the inclusion of the most recent 'Space' domain is the formation of a new NATO Space Centre, within NATO's Air Command in Ramstein, which was announced by Defence Ministers in October of last year. We should remember that NATO's Cooperative Cyber Defence Centre of Excellence was conceived by Estonia in 2004 and established in 2008 and that SHAPE has had its Cyber Operations Centre since 2018. The most

13 Classically, the different armed forces combining to deliver greater effect than their sum.

14 Maritime, land, air, cyberspace and space. 
recent Joint Air Power Competence Centre conference was titled 'Shaping NATO for Multi-Domain Operations of the Future' and has acted as an accelerant to our thinking.

However, there is more to do in terms of MDO. It introduces new challenges and opportunities in equal measure, but reconciling the two will require careful thought—and resources. Conceptually, I would argue it's relatively straightforward to look well ahead and, in broad brush strokes, illustrate the way in which future wars could be fought and how new deterrence could be delivered. Designing a warfighting 'system' for 2040 is not the greatest challenge. ${ }^{15}$ What poses the real complexity is how you form a capability pathway to get there. In often cumbersome procurement cycles and processes, how do we judge the right point to step away from a manned vessel and deliver an unmanned platform? If the capability that operates in different domains is resourced in different government departments, how do we create the right balance of investment decisions to create coherent capabilities? If resources come with control, how will the MDO of the future be commanded? These chewy issues are, helpfully, well surfaced in NATO and our exercise programme-at all levels-now embraces MDO in order that momentum is maintained. It's exciting stuff.

\section{To conclude}

NATO remains, unassailably I would argue, the most successful politicalmilitary alliance in our history. As its membership has continued to broaden, recent thinking around how NATO remains relevant and contemporary has deepened. Longer-range horizon scanning has been captured within NATO 2030, and while the analysis therein is yet to be translated into policy or activity, it opens an aperture for change and further adaptation. More proximate is the work flowing from the NMS, with the DDA acting as the handrail. Within all of this, there are potential strategic departures from NATO's established 'ends, ways and means'. China would be one. Broader interest in a wider Arctic area would be another. Multi-domain operations that consider and embrace space and cyberspace as equal (or even superior) to the more terrestrial domains could define a new 'Revolu-

15 The term 'network centric warfare' was a term with traction in the 1990s, but has been somewhat lost in a blizzard of evolved ideas, most with attendant acronyms. I suggest, however, that it remains a useful anchor point for how we should operate. If one platform underlines this, it's the F35. 
tion of Military Affairs'. This could have strategic consequences for thinking on both deterrence and warfighting. Whether all of this leads to more strategic thought, a new strategy or both is not for me to decide, but the fact it's being spoken of, debated here and, in the case of the DDA, being put into action should all be considered as positive. Any change must, as SACEUR would remind us, be at 'the speed of relevance'. This will continue to require political will, strong leadership and the resources to match. But the other requirement will, as long as the world's oceans constitute over $70 \%$ of the planet's surface, be a strong maritime voice. MARCOM provides that voice for NATO and is immensely proud to do so. 